\title{
Catalytic Dehydration of Glycerol to Acrolein over Aluminum Phosphate Catalysts
}

\author{
Tianlin Ma, ${ }^{\circledR *, \#, a}$ Jianfei Ding, ${ }^{\sharp, b}$ Xueli Liu, ${ }^{a}$ Jiandong Zheng ${ }^{a}$ and Zhi Yun ${ }^{c}$ \\ ${ }^{a}$ School of Materials and Chemical Engineering, Chuzhou University, 239000 Chuzhou, P. R. China \\ ${ }^{b}$ School of Chemistry and Chemical Engineering, Yancheng Institute of Technology, \\ 224051 Yancheng, P. R. China
}

${ }^{c}$ College of Chemical Engineering, Nanjing Tech University, 210009 Nanjing, P. R. China

\begin{abstract}
Gas phase conversion of glycerol to acrolein over a variety of aluminum phosphate (AlP) catalysts synthesized by a simple replacement reaction method with a variation in calcination temperature (300-700 ${ }^{\circ} \mathrm{C}$, AlP-300, AlP-400, AlP-500, AlP-600, and AlP-700, respectively) has been investigated. The textural properties, acidities and coke contents of the samples were also determined. The catalysts were presented in an amorphous state when the AlP sample was calcined below $500{ }^{\circ} \mathrm{C}$. Further increasing the calcination temperature promoted the formation of orthorhombic $\alpha-\mathrm{AlPO}_{4}$ crystal. The weak acid sites increased when the calcination temperature was raised from 300 to $500^{\circ} \mathrm{C}$. However, the weak acid sites decreased when the AlP was calcined above $500{ }^{\circ} \mathrm{C}$. The acidity of the catalyst played a crucial role in the glycerol dehydration reaction. The maximum acrolein selectivity of $66 \%$ at $98 \%$ glycerol conversion was obtained over AlP-500 catalyst, due to the largest number of acid sites and appropriate textural properties. AlP-700 exhibited the lowest glycerol conversion, owing to the formation of orthorhombic $\alpha-\mathrm{AlPO}_{4}$ crystalline phase and the lowest amount of acid sites under high calcination temperature. The significant reduction in the acidity of the used sample led to a decrease of glycerol conversion.
\end{abstract}

Keywords: glycerol, acrolein, dehydration, aluminum phosphate

\section{Introduction}

Nowadays, biodiesel as an important renewable resource has obtained increasing concern. ${ }^{1}$ Glycerol is the major by-product of biodiesel production, which is about $10 \mathrm{wt} . \%$ of the total products. ${ }^{2}$ The applications of glycerol to valuable products have been a research hotspot so far. ${ }^{3}$ Consequently, many researchers ${ }^{1,4-8}$ have focused on designing effective catalysts for conversion of glycerol to acrolein, which is applied widely in the production of textiles, polymers, acrylic acid esters and methionine.

Gas-phase conversion of glycerol is generally considered as an environmentally friendly and economical approach. Various solid acid catalysts have been studied in this important reaction, including phosphates, ${ }^{9}$ metal oxides, ${ }^{4,10}$ zeolites, ${ }^{7,11}$ and heteropolyacids. ${ }^{5,6,12,13}$ Among these acid catalysts, phosphate catalysts have been widely studied in the glycerol dehydration reaction due to its superior catalytic performance. Suprun et al. ${ }^{14}$ reported the catalytic activity

*e-mail: matianlin951@ sina.com

\#These authors contributed equally to this work. of $\mathrm{H}_{3} \mathrm{PO}_{4}$ modified $\mathrm{Al}_{2} \mathrm{O}_{3}$ and $\mathrm{TiO}_{2}$ catalysts. The glycerol conversion on $\mathrm{Al}_{2} \mathrm{O}_{3}-\mathrm{PO}_{4}$ and $\mathrm{TiO}_{2}-\mathrm{PO}_{4}$ was 100 and $98 \%$, respectively. The acrolein selectivity on $\mathrm{Al}_{2} \mathrm{O}_{3}-\mathrm{PO}_{4}$ and $\mathrm{TiO}_{2}-\mathrm{PO}_{4}$ was 42 and $37 \%$, respectively, and the catalysts deactivated slowly. Deleplanque et al..$^{15}$ obtained $100 \%$ glycerol conversion and $92 \%$ acrolein selectivity using $\mathrm{FePO}_{4}$ as catalyst. Estevez et al. ${ }^{16}$ prepared the mesoporous $\mathrm{AlPO}_{4}$ by a simple ammonia sol-gel method. The $\mathrm{AlPO}_{4}{ }^{-}$ 650 showed the maximum acrolein yield $(23 \%)$ at $270{ }^{\circ} \mathrm{C}$ and 1 bar pressure. Estevez and co-workers ${ }^{17}$ also studied the influence of a transition metal $(\mathrm{Cu}, \mathrm{Co}, \mathrm{Cr}, \mathrm{Fe})$ in the dispersion phase of $\mathrm{AlPO}_{4}$, obtaining the maximum acrolein yield (54\%) on AlCoPO650. Many studies demonstrated that the catalytic performance was associated with the calcination temperature of the phosphate catalysts. However, the aforementioned papers did not investigate the influence of calcination temperatures on catalyst structure and performance in detail, which could not reveal the propertyactivity relationship.

In the present paper, aluminum phosphate catalysts were synthesized using a simple replacement reaction method with a variation of calcination temperature $\left(300-700{ }^{\circ} \mathrm{C}\right)$. 
The purpose of this work is to investigate changes in the structure, acidity amount, acidity strength and acid type of the catalysts as a function of calcination temperature and to find the correlation between the surface properties of catalysts and catalytic activities during the glycerol dehydration reaction.

\section{Experimental}

\section{Catalyst preparation}

All necessary chemicals were purchased from Aladdin Chemistry Co., Ltd. (Shanghai, China), and used without further purification. Aluminum phosphate (AlP) was prepared by a simple replacement reaction method from $\mathrm{Al}\left(\mathrm{NO}_{3}\right)_{3} \cdot 9 \mathrm{H}_{2} \mathrm{O}$ and $\mathrm{Na}_{3} \mathrm{PO}_{4} \cdot 12 \mathrm{H}_{2} \mathrm{O}$. Firstly, $61 \mathrm{~g}$ of $\mathrm{Al}\left(\mathrm{NO}_{3}\right)_{3} \cdot 9 \mathrm{H}_{2} \mathrm{O}$ and $61.8 \mathrm{~g}$ of $\mathrm{Na}_{3} \mathrm{PO}_{4} \cdot 12 \mathrm{H}_{2} \mathrm{O}$ were added to $350 \mathrm{~mL}$ of deionized water in a $500 \mathrm{~mL}$ of round-bottom flask under stirring. The solution was stirred at $100{ }^{\circ} \mathrm{C}$ for $5 \mathrm{~h}$ until no more precipitate formed. After the solution was cooled to room temperature, the solution was filtrated and washed with deionized water twenty times. The solid obtained was dried at $120{ }^{\circ} \mathrm{C}$ for $12 \mathrm{~h}$ and calcined at different temperatures $\left(300,400,500,600\right.$, and $\left.700{ }^{\circ} \mathrm{C}\right)$ for $4 \mathrm{~h}$ in a muffle furnace at a heating rate of $5{ }^{\circ} \mathrm{C} \mathrm{min}{ }^{-1}$ prior to reaction. The resulting material was denoted as AlP-T, where $\mathrm{T}$ represented the calcination temperature. For comparison, the AlP sample without calcination was also prepared.

\section{Catalyst characterization}

X-ray diffraction (XRD) data was obtained using a Shimadzu XRD-6000 instrument with $\mathrm{Cu} \mathrm{K} \alpha$ radiation operated at $40 \mathrm{kV}$ and $40 \mathrm{~mA}$. The specific surface area, pore volume and pore size of catalysts were determined by a Micromeritics ASAP 2020 instrument. Temperature programmed desorption of ammonia $\left(\mathrm{NH}_{3}\right.$-TPD) analysis was carried out on a Builder PCA-1200 instrument, and the amount of acid sites was calculated by quantifying the desorbed $\mathrm{NH}_{3}$ from $\mathrm{NH}_{3}$-TPD. Fourier transformed infrared spectroscopy (FTIR) of pyridine adsorption experiments were analyzed by a Shimadzu FTIR-8700 spectrometer. The coke content of the used catalysts was obtained for elemental characterization on a CHNS analyzer (Vario EL III).

\section{Catalytic reaction}

The catalytic performance of samples was conducted for the dehydration of glycerol using a vertical fixed-bed reactor at atmospheric pressure. The reactor length was $50 \mathrm{~cm}$ and its inner diameter was $8 \mathrm{~mm} .1 \mathrm{~g}$ of catalyst was placed in the middle part of the reactor and quartz wool was put at both ends. Prior to the reaction, the catalyst was pretreated at $280{ }^{\circ} \mathrm{C}$ under nitrogen flow $\left(40 \mathrm{~mL} \mathrm{~min}{ }^{-1}\right)$ for about $1 \mathrm{~h}$. Liquid aqueous glycerol (10 wt.\%) was injected by a syringe pump with $0.08 \mathrm{~mL} \mathrm{~min}{ }^{-1}$ flow-rate in a $\mathrm{N}_{2}$ flow $\left(10 \mathrm{~mL} \mathrm{~min}^{-1}\right)$. The reaction temperature was fixed at $280{ }^{\circ} \mathrm{C}$ for all reactions. After $1 \mathrm{~h}$, the products and unconverted glycerol were condensed in a water-ice mixture and taken hourly for analysis.

The analysis was performed using a gas chromatograph (GC) equipped with a capillary column (HP-INNOWAX; $60 \mathrm{~m} \times 0.32 \mathrm{~mm} \times 0.25 \mu \mathrm{m}$ ) and flame ionization detector (FID) using methanol as an internal standard. Glycerol conversion and product selectivities were defined as follows:

$$
\begin{aligned}
& \text { Glycerol conversion }(\%)=\frac{\text { Moles of glycerol reacted }}{\text { Moles of glycerol in the feed }} \times 100 \\
& \text { Product selectivity }(\%)=\frac{\text { Moles of carbon in a product formed }}{\text { Moles of carbon in glycerol consumed }} \times 100 \\
& \text { Acrolein yield }(\%)=\frac{\text { Glycerol conversion } \times \text { acrolein selectivity }}{100}
\end{aligned}
$$

\section{Results and Discussion}

\section{Catalyst characterization}

The XRD patterns of AlP and AlP-T catalysts are illustrated in Figure 1. When the AlP catalyst is calcined below $500{ }^{\circ} \mathrm{C}$, there is only a very broad peak between $15-40^{\circ}$, indicating that the catalysts are presented in an amorphous state. On calcination at $600^{\circ} \mathrm{C}$, the characteristic diffraction peaks of the orthorhombic $\alpha-\mathrm{AlPO}_{4}$ crystalline phase at $2 \theta$ angles of $20.3,21.5,23.0$, and $35.6^{\circ}$ are appeared. ${ }^{18}$ With further raising calcination temperature to $700{ }^{\circ} \mathrm{C}$, the intensities of the XRD diffraction peaks of the orthorhombic $\alpha-\mathrm{AlPO}_{4}$ crystalline phase increase. From the above results, it can be concluded that the $\mathrm{AlPO}_{4}$ remains in an amorphous state when the calcination temperature is lower than $600{ }^{\circ} \mathrm{C}$. Further increasing the calcination temperature facilitates the formation of orthorhombic $\alpha-\mathrm{AlPO}_{4}$ crystalline phase. Similar XRD results on $\mathrm{AlPO}_{4}$ were observed by Liu et al. ${ }^{18}$ and Mohamed et al. ${ }^{19}$ Moreover, Lopez-Pedrajas et al..$^{20}$ found that the amorphous $\mathrm{AlPO}_{4}$ showed higher performance in the glycerol dehydration reaction than the other highly crystalline metal phosphates.

Figure 2 illustrates the $\mathrm{N}_{2}$ adsorption-desorption isotherms of AlP and AlP-T samples. Figure 3 shows the 


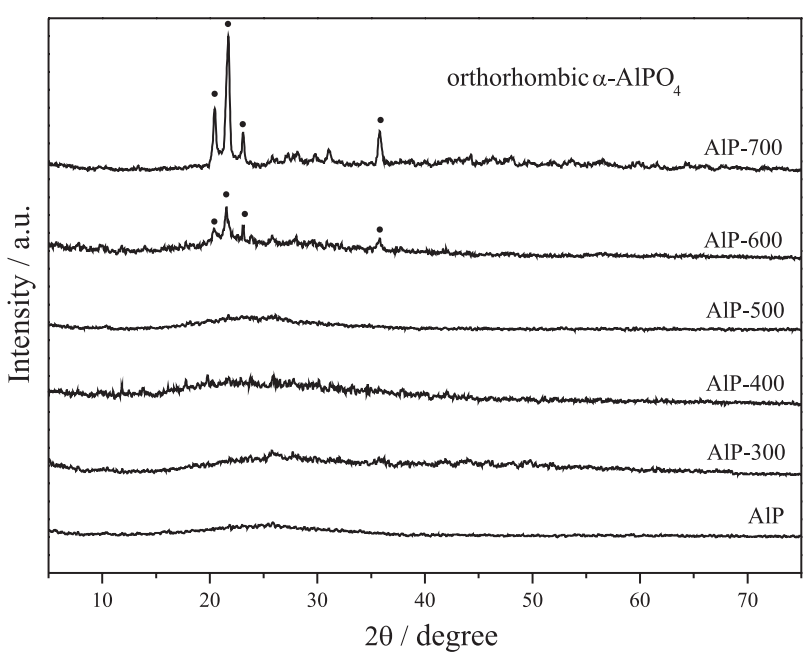

Figure 1. XRD patterns of the AlP and AlP-T samples.

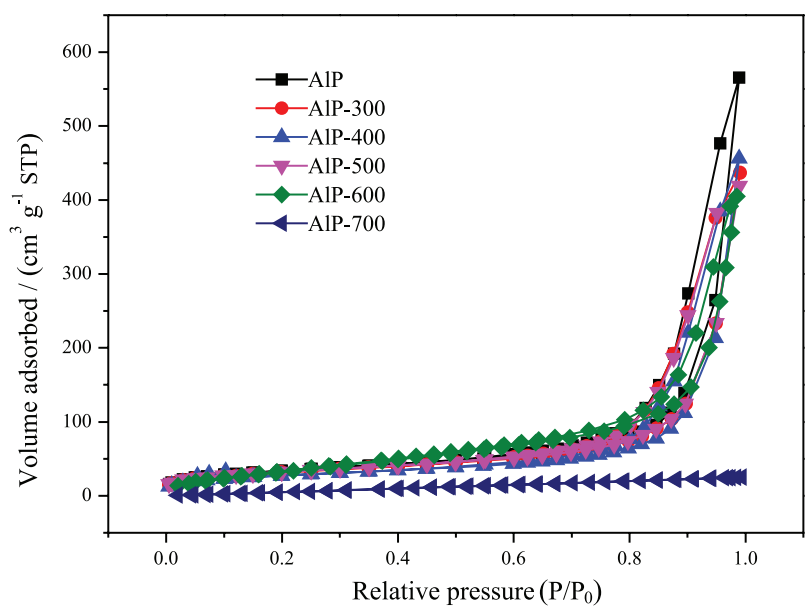

Figure 2. Nitrogen adsorption-desorption isotherms of the AlP and AlP-T samples.

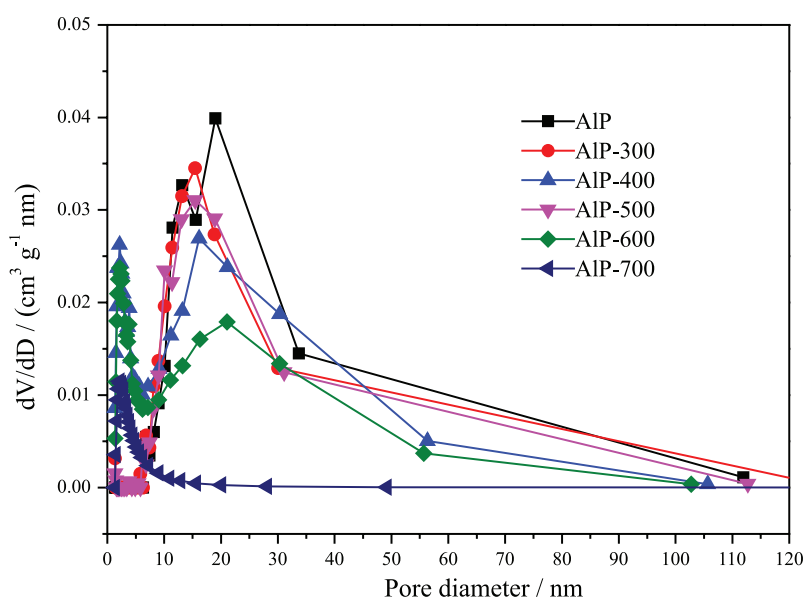

Figure 3. Pore diameter distributions of the AlP and AlP-T samples.

pore diameter distributions of AlP and AlP-T samples. Compared with the AlP, the shape of the isotherm after calcination at $300,400,500$ and $600{ }^{\circ} \mathrm{C}$ does not show obvious change. However, the uptake of the isotherm at a relative pressure higher than 0.8 disappears at $700{ }^{\circ} \mathrm{C}$, indicating the elimination of mesopores, which is due to the formation of orthorhombic $\alpha-\mathrm{AlPO}_{4}$ crystalline phase under high calcination temperature. ${ }^{18,19}$ The textural properties of the samples were calculated from $\mathrm{N}_{2}$ physical adsorption-desorption measurements and the results are listed in Table 1. The surface area decreases when the AlP is calcined from 300 to $500{ }^{\circ} \mathrm{C}$, which is due to large shrinkage. ${ }^{21}$ When the AlP is calcined at $600{ }^{\circ} \mathrm{C}$, the surface area immediately increases to $202 \mathrm{~m}^{2} \mathrm{~g}^{-1}$, and then decreases to $52 \mathrm{~m}^{2} \mathrm{~g}^{-1}$ with further raising the calcination temperature. The increase of surface area at $600{ }^{\circ} \mathrm{C}$ is attributed to the formation of orthorhombic $\alpha-\mathrm{AlPO}_{4}$ crystal and the decrease of surface area at $700{ }^{\circ} \mathrm{C}$ is owing to the growth of nanocrystals and sintering of skeletons. Meanwhile, the pore volume and pore size decrease with increase of calcination temperature, which are similar to the results reported by Mohamed et al. ${ }^{19}$ and $\mathrm{Li}$ et al. ${ }^{21}$ Moreover, Estevez et al. ${ }^{16}$ reported that appropriate textural properties could increase the catalytic performance in the dehydration of glycerol to acrolein.

Table 1. Textural properties of the AlP and AlP-T catalysts

\begin{tabular}{lccc}
\hline Catalyst & $\begin{array}{c}\text { Surface area / } \\
\left(\mathrm{m}^{2} \mathrm{~g}^{-1}\right)\end{array}$ & $\begin{array}{c}\text { Pore volume / } \\
\left(\mathrm{cm}^{3} \mathrm{~g}^{-1}\right)\end{array}$ & Pore size / nm \\
\hline AlP $^{\mathrm{a}}$ & 153 & 0.89 & 18.992 \\
$\mathrm{AlP}^{-300}{ }^{\mathrm{a}}$ & 141 & 0.69 & 15.651 \\
$\mathrm{AlP}^{-400}{ }^{\mathrm{a}}$ & 138 & 0.68 & 16.122 \\
AlP-500 $^{\mathrm{a}}$ & 135 & 0.66 & 15.462 \\
AlP-600 $^{\mathrm{a}}$ & 202 & 0.65 & 2.167 \\
AlP-700 $^{\mathrm{a}}$ & 52 & 0.05 & 2.164 \\
\hline
\end{tabular}

${ }^{\mathrm{a}} \mathrm{AlPO}_{4}$ and $\mathrm{AlPO}_{4}$ calcined at $300,400,500,600$, and $700{ }^{\circ} \mathrm{C}$.

The acidity of catalyst measured by $\mathrm{NH}_{3}$-TPD is an important parameter in glycerol dehydration reaction. The $\mathrm{NH}_{3}$-TPD profiles of AlP and AlP-T samples are revealed in Figure 4. The strength of acid sites on the sample is proportional to the desorption temperature. The desorption profiles of the catalysts show a broad peak at about $204{ }^{\circ} \mathrm{C}$ in the range of $150-350{ }^{\circ} \mathrm{C}$ except for the AlP700 sample, which is due to weak acid sites. Compared to the AlP, AlP-300 catalyst shows more weak acid sites, suggesting that appropriate calcination temperature can increase the acid sites of AlP. The weak acid sites increase when the calcination temperature is increased from 300 to $500{ }^{\circ} \mathrm{C}$, which is due to the occurrence of dehydroxylation including the removal of $-\mathrm{OH}$ groups. ${ }^{21}$ However, the weak acid sites decrease when the AlP is calcined above $500{ }^{\circ} \mathrm{C}$, probably owing to partial decomposition of weak acid sites and sintering of the AlP. These results 
are similar to the findings of Mohamed et al., ${ }^{19}$ who reported that the acid value increased with increasing the calcination temperature from 350 to $450{ }^{\circ} \mathrm{C}$. A further increase in the calcination temperature led to a decrease in these acid values. The acidity of the catalysts are in an order of AlP-500 > AlP-400 > AlP-300 > AlP > AlP-600 $>$ AlP-700. It is worth noting that many researchers ${ }^{6,14,22}$ reported that the glycerol conversion depended on the acidity of the catalyst.

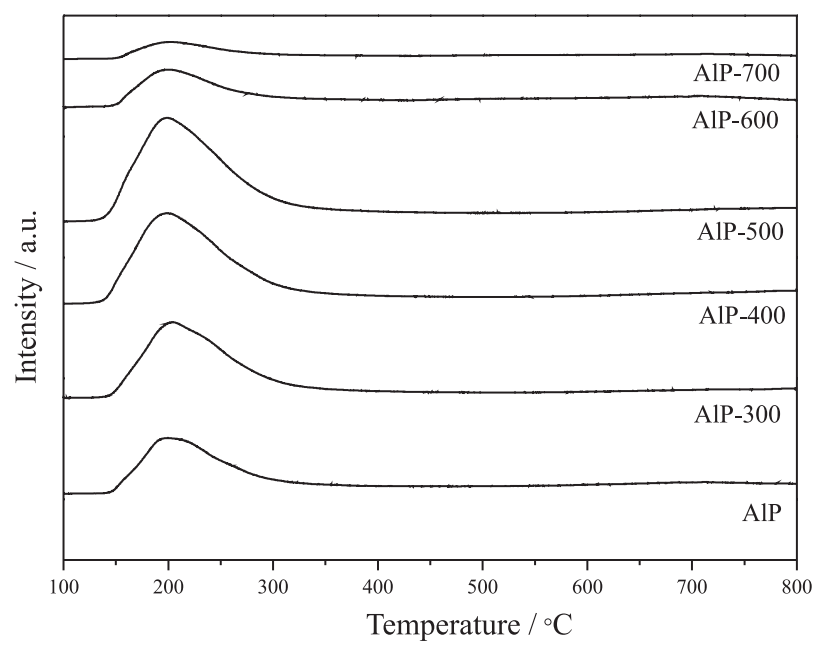

Figure 4. $\mathrm{NH}_{3}$-TPD profiles of the AlP and AlP-T samples.

Many researchers ${ }^{6,13,14}$ reported that Brønsted and Lewis acid sites influenced the product distribution in the glycerol dehydration reaction. Therefore, pyridine-FTIR experiments were conducted to determine the Brønsted and Lewis acid sites. The pyridine-FTIR spectra of AlP and AlP-T samples are shown in Figure 5. The peak at approximately 1448 and $1540 \mathrm{~cm}^{-1}$ is due to Lewis and Brønsted acid sites, respectively. The Brønsted and Lewis acid sites are present on AlP, AlP-300, AlP-400 and

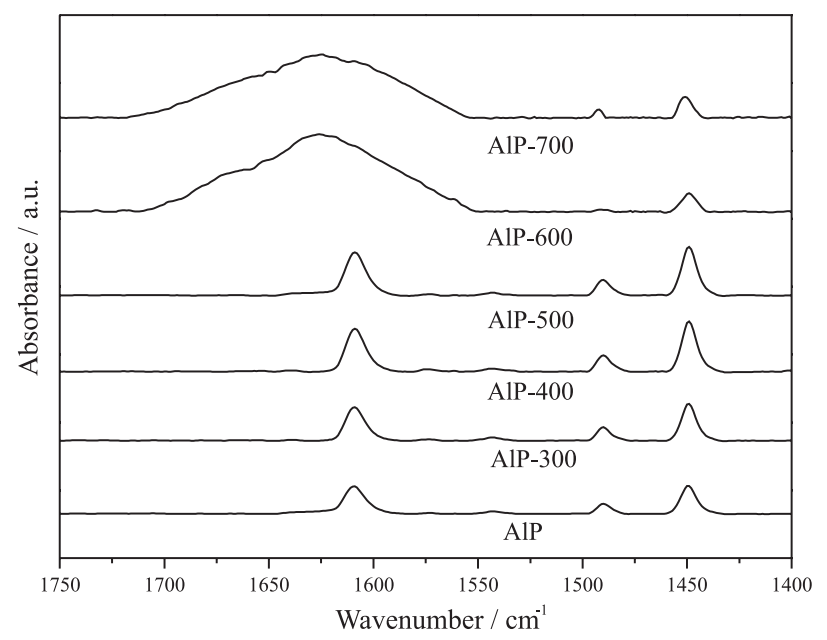

Figure 5. Pyridine-FTIR spectra of the AlP and AlP-T samples.
AlP-500, while AlP-600 and AlP-700 only show Lewis acid sites. The Lewis acid sites increase and the Brønsted acid sites show no obvious change when the calcination temperature is increased to $500{ }^{\circ} \mathrm{C}$. The Lewis acid sites decrease when the AlP is calcined above $500{ }^{\circ} \mathrm{C}$.

\section{Catalytic activity}

The catalytic results of AlP and AlP-T samples at $280^{\circ} \mathrm{C}$ and $2 \mathrm{~h}$ reaction time are listed in Table 2. Acrolein is the main product in the dehydration of glycerol over all the catalysts. Moreover, some byproducts including hydroxyacetone, formaldehyde, acetaldehyde and acetic acid are detected. The glycerol conversion $(45 \%)$ and acrolein selectivity $(25 \%)$ are very low under blank reaction conditions. The AlP and AlP-T samples show higher glycerol conversion and acrolein selectivity than the blank reaction. When the calcination temperature is raised to $500{ }^{\circ} \mathrm{C}$, the glycerol conversion is enhanced from 87 to $98 \%$, which is proportional to the acidity of samples according to the $\mathrm{NH}_{3}$-TPD results. The AlP-500 sample gives the highest glycerol conversion of $98 \%$, acrolein selectivity of $66 \%$, and acrolein yield of $65 \%$. This is because AlP-500 has the largest number of acid sites and appropriate textural properties. These results indicate that the catalyst acidity and appropriate textural properties are crucial parameters for obtaining superior results in this reaction, consistent with the previous reports. ${ }^{16,23}$ With further raising calcination temperature to $700{ }^{\circ} \mathrm{C}$, the glycerol conversion, acrolein selectivity and acrolein yield decrease. This can be owing to the following reasons: $(i)$ the formation of orthorhombic $\alpha-\mathrm{AlPO}_{4}$ crystalline phase under high calcination temperature; (ii) changes in the textural properties including decreased surface areas, pore volumes and pore sizes under high calcination temperature; and (iii) the decrease of acid sites under high calcination temperature. Moreover, many researchers ${ }^{6,13,14}$ found that the Brønsted acid sites were beneficial to produce acrolein. However, the correlation of Brønsted acid sites and acrolein selectivity is not found in this study. In the dehydration of glycerol to acrolein, water is present at a relatively high temperature, some Lewis acidic sites interacting with steam present in the system are converted to Brønsted ones to yield more acrolein. ${ }^{24}$

A comparison of the catalytic performance of different metal phosphate catalysts in the gas phase dehydration of glycerol to acrolein is shown in Table 3 . The iron phosphate prepared by hydrothermal method $\left(\mathrm{FePO}_{4}-\mathrm{H}\right)$ showed the best catalytic performance, with $100 \%$ glycerol conversion and $92 \%$ acrolein yield after $5 \mathrm{~h}$ of reaction. ${ }^{15}$ The $\mathrm{ZrP}-400$ exhibited lower acrolein yield (81.5\%) than $\mathrm{FePO}_{4}-\mathrm{H}$. 
Table 2. Catalytic performances of the AlP and AlP-T samples at $280{ }^{\circ} \mathrm{C}$ and $2 \mathrm{~h}$ reaction time

\begin{tabular}{|c|c|c|c|c|c|c|c|c|}
\hline \multirow{2}{*}{ Catalyst } & \multirow{2}{*}{$\mathrm{X}^{\mathrm{a}} / \%$} & \multirow{2}{*}{$\mathrm{Y}^{\mathrm{b}} / \%$} & \multicolumn{6}{|c|}{ Selectivity / \% } \\
\hline & & & Acrolein & Hydroxyacetone & Acetaldehyde & Formaldehyde & Acetic acid & Others \\
\hline Blank & 45 & 11 & 25 & 8 & 6 & 5 & 8 & 48 \\
\hline $\mathrm{AlP}^{\mathrm{c}}$ & 87 & 52 & 60 & 14 & 13 & 5 & 2 & 6 \\
\hline AlP- $300^{c}$ & 91 & 53 & 58 & 16 & 14 & 3 & 2 & 7 \\
\hline AlP- $400^{c}$ & 94 & 54 & 57 & 18 & 14 & 3 & 1 & 7 \\
\hline AlP- $500^{c}$ & 98 & 65 & 66 & 11 & 15 & 2 & 2 & 4 \\
\hline AlP- $600^{c}$ & 72 & 45 & 62 & 5 & 20 & 5 & 3 & 5 \\
\hline AlP- $700^{c}$ & 41 & 20 & 49 & 7 & 24 & 4 & 4 & 12 \\
\hline
\end{tabular}

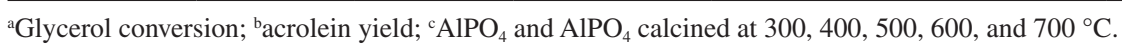

Meanwhile, it can be seen that AlP-500 prepared by a simple replacement reaction method in this work shows higher catalytic performance than other metal phosphate catalysts except for $\mathrm{FePO}_{4}-\mathrm{H}$ and $\mathrm{ZrP}-400$.

Figure 6 shows the catalytic performance of AlP and AlP-T samples calcined at different temperatures with time on stream (TOS) at $280{ }^{\circ} \mathrm{C}$. The results show that AlP-500 sample gives the highest glycerol conversion during $6 \mathrm{~h}$ of reaction, which can be attributed to that AlP-500 has the largest number of acid sites and appropriate textural properties. AlP-400 shows lower glycerol conversion than AlP-500 during $6 \mathrm{~h}$ of reaction. In addition, AlP-700 exhibits the lowest glycerol conversion during $6 \mathrm{~h}$ of reaction, attributed to the formation of orthorhombic $\alpha-\mathrm{AlPO}_{4}$ crystalline phase and the decrease of acid sites under high calcination temperature. It is worth noting that glycerol conversion reduces with time on stream, due to the catalyst deactivation by carbon deposition, which is the major cause of deactivation over solid acids catalysts during glycerol dehydration reaction. ${ }^{1,6}$ Among the catalysts,
AlP-500 shows the highest acrolein selectivity and yield and AlP-700 exhibits the lowest acrolein selectivity and yield during $6 \mathrm{~h}$ of reaction. The catalytic results show that there is not significant difference among obtained acrolein selectivities over AlP, AlP-300, AlP-400, and AlP-600, maybe due to their similar textural properties. It is also noticed that acrolein selectivity and yield of the catalysts show no obvious decrease with time on stream. Similar results were reported by dos Santos et al. ${ }^{26}$ Moreover, the trends of acrolein selectivity and yield of AlP and AlP-T samples calcined at different temperatures are not directly correlated with the trend of total acidities and Brønsted acid sites of the samples.

\section{Time-on-stream studies of the AIP-500}

The glycerol conversion and acrolein selectivity change with TOS was investigated over the AlP-500 catalyst at $280{ }^{\circ} \mathrm{C}$ (Figure 7). The glycerol conversion reduces from 98 to $80 \%$ and the acrolein selectivity keeps relative stable

Table 3. Comparison of catalytic performance of different metal phosphates catalysts in the gas phase dehydration of glycerol to acrolein

\begin{tabular}{|c|c|c|c|c|c|c|}
\hline Catalyst & $\begin{array}{c}\text { Reaction } \\
\text { temperature } /{ }^{\circ} \mathrm{C}\end{array}$ & Reaction time / $\mathrm{h}$ & $\mathrm{X}_{\text {glycerol }}{ }^{\mathrm{a}} / \%$ & $\mathrm{~S}_{\text {acrolein }}{ }^{\mathrm{b}} / \%$ & $\mathrm{Y}_{\text {acrolein }} \mathrm{c} / \%$ & Reference \\
\hline $\mathrm{Al}_{2} \mathrm{O}_{3}-\mathrm{PO}_{4}$ & 280 & 1 & 100 & 42 & 42 & 14 \\
\hline $\mathrm{TiO}_{2}-\mathrm{PO}_{4}$ & 280 & 1 & 98 & 37 & 36 & 14 \\
\hline $\mathrm{FePO}_{4}-\mathrm{H}$ & 280 & 5 & 100 & 92.1 & 92.1 & 15 \\
\hline $\mathrm{Ca} / \mathrm{HAP}$ & 350 & 2 & 85 & 9 & 7 & 9 \\
\hline ZrP-400 & 315 & 10 & 100 & 81.5 & 81.5 & 25 \\
\hline $\mathrm{AlPO}_{4} 450$ & 280 & 3 & 41 & 49 & 20 & 17 \\
\hline $\mathrm{AlCoPO} 450$ & 280 & 3 & 86 & 51 & 44 & 17 \\
\hline $\mathrm{AlCuPO} 450$ & 280 & 3 & 77 & 60 & 46 & 17 \\
\hline AlP-500 & 280 & 2 & 98 & 66 & 65 & this work \\
\hline
\end{tabular}

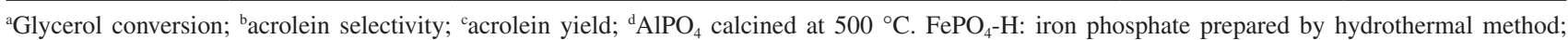
HAP: hydroxyapatite; ZrP-400: zirconium phosphate calcined at $400{ }^{\circ} \mathrm{C}$; AlPO4450: aluminum phosphate prepared by sol-gel method calcined at $450{ }^{\circ} \mathrm{C}$; AlCoPO450: adding $\mathrm{Co}$ in the dispersion phase of $\mathrm{AlPO}_{4}$ calcined at $450{ }^{\circ} \mathrm{C}$; $\mathrm{AlCuPO} 450$ : adding $\mathrm{Cu}$ in the dispersion phase of $\mathrm{AlPO} 4 \mathrm{calcined}$ at $450{ }^{\circ} \mathrm{C}$. 

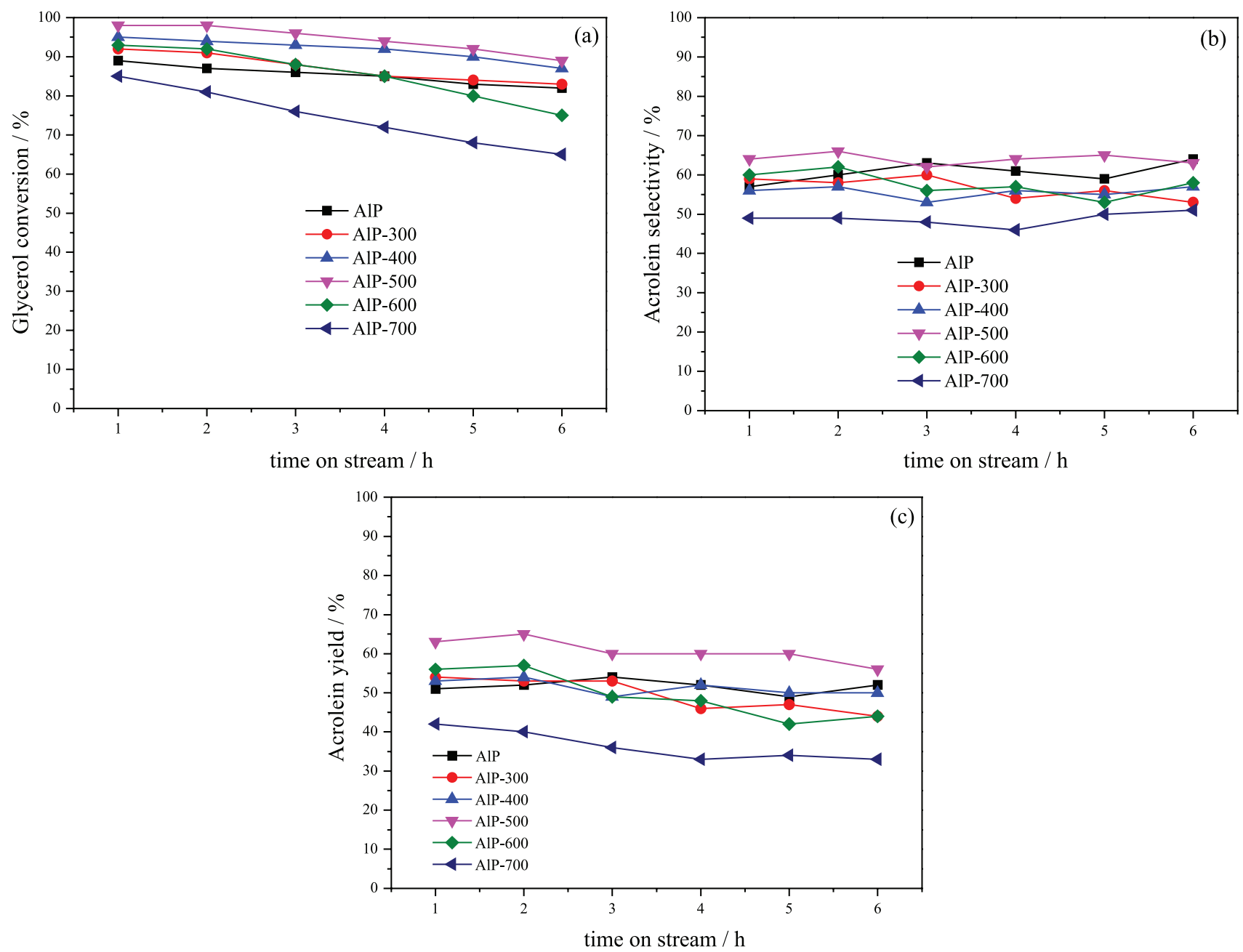

Figure 6. (a) Glycerol conversion; (b) acrolein selectivity; (c) acrolein yield over the AlP and AIP-T samples.

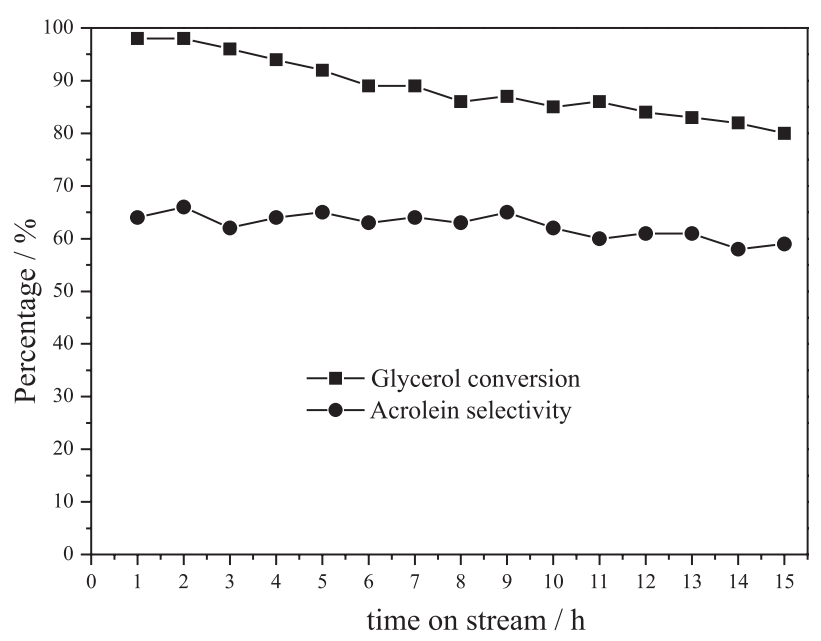

Figure 7. Time-on-stream studies over the AlP-500 catalyst.

after reaction for $15 \mathrm{~h}$. The decrease in glycerol conversion is due to the catalyst deactivation by carbon deposition. ${ }^{1,6}$ The coke content of used AlP-500 catalyst was measured by a CHNS analyzer, and about $1.4 \mathrm{wt} . \%$ carbon was deposited after $15 \mathrm{~h}$ of reaction. The spent AlP-500 after $15 \mathrm{~h}$ of reaction was characterized by $\mathrm{XRD}$ and $\mathrm{NH}_{3}$-TPD to study the information about the changes of the structure and acid sites of the catalyst during the reaction. The XRD patterns of the fresh and spent AlP-500 catalysts are shown in Figure 8. The result clearly indicates that the structure of AlP-500 catalyst is maintained after the glycerol dehydration reaction. The $\mathrm{NH}_{3}$-TPD profiles of the fresh and used AlP-500 catalysts are shown in Figure 9. The used AlP-500 shows fewer acid sites than fresh AlP-500. This result suggests that the decrease of the acidity of AlP-500 caused by carbon deposition reduces the glycerol conversion considerably.

\section{Conclusions}

In this work, a series of aluminum phosphates samples were synthesized by a simple replacement reaction method with a variation of calcination temperature for acid catalyzed glycerol dehydration reaction. When the 


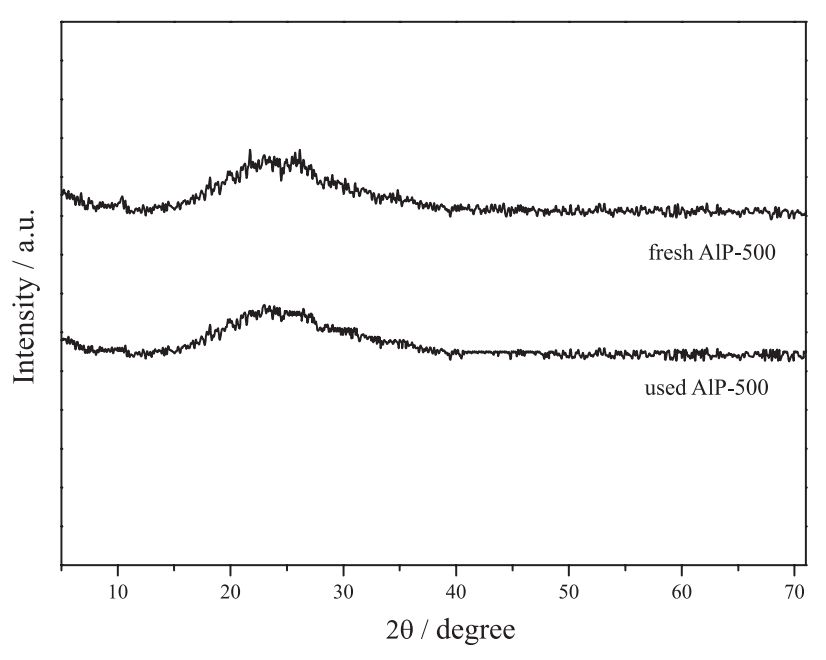

Figure 8. XRD patterns of the fresh and used AlP-500 catalysts.

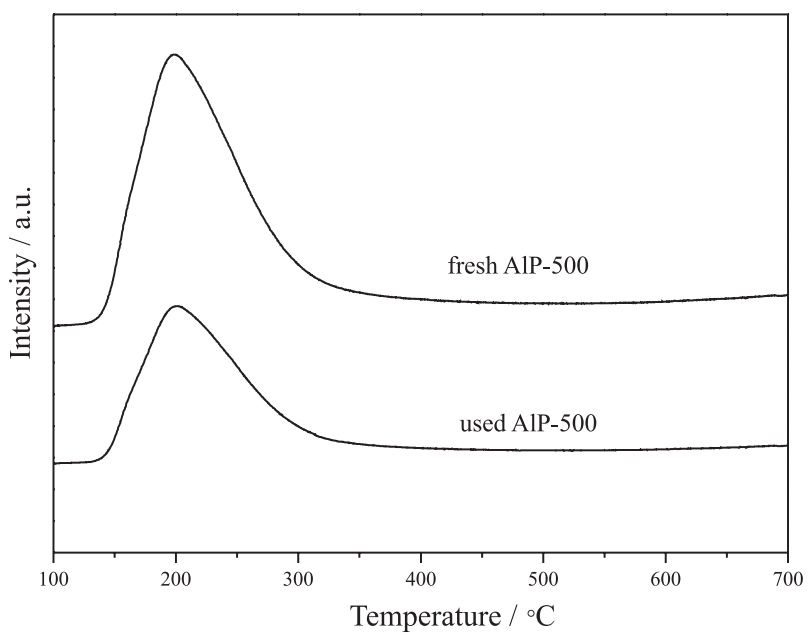

Figure 9. $\mathrm{NH}_{3}$-TPD profiles of the fresh and used AlP-500 catalysts.

AlP sample was calcined below $500{ }^{\circ} \mathrm{C}$, the catalysts were presented in an amorphous state. Further raising the calcination temperature promoted the formation of orthorhombic $\alpha-\mathrm{AlPO}_{4}$ crystal. The weak acid sites increased when the calcination temperature was raised from 300 to $500{ }^{\circ} \mathrm{C}$, which was ascribed to the occurrence of dehydroxylation including the removal of $-\mathrm{OH}$ groups. However, the weak acid sites decreased when the AlP was calcined above $500{ }^{\circ} \mathrm{C}$, probably owing to partial decomposition of weak acid sites and sintering of the AlP. The acidity of the catalyst played a crucial role in the glycerol dehydration reaction. AlP-500 catalyst showed the highest glycerol conversion of $98 \%$, acrolein selectivity of $66 \%$, and acrolein yield of $65 \%$. This was because AlP-500 had the largest number of acid sites and appropriate textural properties. AlP-700 exhibited the lowest glycerol conversion, owing to the formation of orthorhombic $\alpha-\mathrm{AlPO}_{4}$ crystalline phase and the lowest amount of acid sites under high calcination temperature.
The significant decrease in the acidity of the spent sample led to a decrease in the glycerol conversion.

\section{Acknowledgments}

This work was supported by the University Natural Science Research Key Project of Anhui Province (KJ2018A0435, KJ2017A412), the University Natural Science Research General Project of Anhui Province (KJ2018B15), Scientific Research Start Foundation Project of Chuzhou University (2017qd12 and 2017qd15), and Anhui Provincial Natural Science Foundation (1808085MB50).

\section{References}

1. Talebian-Kiakalaieh, A.; Amin, N. A. S.; Renewable Energy 2017, 114, 794.

2. Anitha, M.; Kamarudin, S. K.; Kofli, N. T.; Chem. Eng. J. 2016, 295, 119.

3. Chagas, P.; Thibau, M. A.; Breder, S.; Souza, P. P.; Caldeira, G. S.; Portilho, M. F.; Castro, C. S.; Oliveira, L. C. A.; Chem. Eng. J. 2019, 369, 1102.

4. Chai, S.; Wang, H.; Liang, Y.; Xu, B.; Green Chem. 2017, 9 , 1130.

5. Shen, L.; Yin, H.; Wang, A.; Feng, Y.; Shen, Y.; Wu, Z.; Jiang, T.; Chem. Eng. J. 2012, 180, 277.

6. Ma, T.; Yun, Z.; Xu, W.; Chen, L.; Li, L.; Ding, J.; Shao, R.; Chem. Eng. J. 2016, 294, 343.

7. Ren, X.; Zhang, F.; Sudhakar, M.; Wang, N.; Dai, J.; Liu, L.; Catal. Today 2019, 332, 20.

8. Pagliaro, M.; Ciriminna, R.; Kimura, H.; Rossi, M.; Pina, C. D.; Angew. Chem., Int. Ed. 2007, 46, 4434.

9. Stošić, D.; Bennici, S.; Sirotin, S.; Calais, C.; Couturier, J.; Dubois, J.; Travert, A.; Auroux, A.; Appl. Catal., A 2012, 447448, 124.

10. Sung, K. H.; Cheng, S.; RSC Adv. 2017, 7, 41880.

11. Fernandes, A.; Ribeiro, M. F.; Lourenço, J. P.; Catal. Commun. 2017, 95, 16.

12. Talebian-Kiakalaieh, A.; Amin, N. A. S.; Zakaria, Z. Y.; J. Ind. Eng. Chem. 2016, 34, 300.

13. Ding, J.; Ma, T.; Cui, M.; Shao, R.; Guan, R.; Wang, P.; Mol. Catal. 2018, 461, 1.

14. Suprun, W.; Lutecki, M.; Haber, T.; Papp, H.; J. Mol. Catal. A: Chem. 2009, 309, 71.

15. Deleplanque, J.; Dubois, J.-L.; Devaux, J.-F.; Ueda, W.; Catal. Today 2010, 157, 351.

16. Estevez, R.; Lopez-Pedrajas, S.; Blanco-Bonilla, F.; Luna, D.; Bautista, F. M.; Chem. Eng. J. 2015, 282, 179.

17. Lopez-Pedrajas, S.; Estevez, R.; Blanco-Bonilla, F.; Luna, D.; Bautista, F. M.; J. Chem. Technol. Biotechnol. 2017, 92, 2661. 
18. Liu, B.; Jiang, P.; Zhang, P.; Zhao, H.; Huang, J.; C. R. Chim. 2017, 20, 540 .

19. Mohamed, F. S.; Kiwan, H. H.; Mostafa, M. R.; Adsorpt. Sci. Technol. 2002, 20, 131.

20. Lopez-Pedrajas, S.; Estevez, R.; Navarro, R.; Luna, D.; Bautista, F. M.; J. Mol. Catal. A: Chem. 2016, 421, 92.

21. Li, W.; Zhu, Y.; Guo, X.; Nakanishi, K.; Kanamori, K.; Yang, H.; Sci. Technol. Adv. Mater. 2013, 14, 045007.

22. Ma, T.; Ding, J.; Shao, R.; Xu, W.; Yun, Z.; Chem. Eng. J. 2017, $316,797$.
23. Hamid, S. B. A.; Daud, N. A.; Suppiah, D. D.; Yehya, W. A.; Sudarsanam, P.; Bhargava, S. K.; Polyhedron 2016, 120, 154.

24. Alhanash, A.; Kozhevnikova, E. F.; Kozhevnikov, I. V.; Appl. Catal., A 2010, 378, 11.

25. Gan, H.; Zhao, X.; Song, B.; Guo, L.; Zhang, R.; Chen, C.; Chen, J.; Zhu, W.; Hou, Z.; Chin. J. Catal. 2014, 35, 1148.

26. dos Santos, M. B.; Andrade, H. M. C.; Mascarenhas, A. J. S.; Microporous Mesoporous Mater. 2016, 223, 105.

Submitted: December 25, 2019

Published online: March 17, 2020 